\title{
Pensonomonoor
}

2015, vol. 74, 85-94

http://dx.doi.org/10.12657/denbio.074.009

\author{
Huiquan Zheng*, Hongjing Duan*, Dehuo Hu, Yun Li, Yubao Hao
}

\section{Genotypic variation of Cunninghamia lanceolata revealed by phenotypic traits and SRAP markers}

\author{
Received: 20 November 2014; Accepted: 23 March 2015
}

\begin{abstract}
The success of a tree breeding program largely depended on the available genetic variability of the germplasms. Our present study aimed to assess the phenotypic variation and DNA variability using sequence-related amplified polymorphism (SRAP) markers among 50 Cunninghamia lanceolata (Chinese fir) genotypes. Extensive phenotypic variations ( $p<0.05$ or 0.01 ) were found for all the growth and wood property traits (height, diameter at breast height, stem volume, and wood basic density, hygroscopicity, heart-wood ratio, tracheid length, tracheid diameter and tracheid length-diameter ratio) with coefficients of variation spanning from 6.8 to $31.3 \%$. At the DNA level, thirty-five SRAP primer combinations produced 498 bands with $89.4 \%$ polymorphism across genotypes; moreover, the Nei's gene diversity was detected to be ranged between 0.204 and 0.373 (mean $=0.279$ ), while the Shannon's Information Index stretched from 0.324 to 0.555 with an average value of 0.427 . Significance $(\mathrm{p}<0.01)$ of the variability of SRAP polymorphism among genotypes was further demonstrated by AMOVA. These results indicated a relatively high level of genetic diversity in genotypes. The SRAP' dendrogram additionally revealed that these genotypes could be split into 7 clusters with higher discriminating capacity over that of phenotype. Notably, a total of 99 statistically significant $(\mathrm{p}<0.05)$ marker-trait associations related to the growth and wood property traits were identified. These marker-trait associations corresponded to 77 different SRAP markers with $R^{2}$ (percentage of the phenotypic variation explained by marker) ranging from 8.3 to $26.4 \%$.
\end{abstract}

Additional key words: Chinese fir, wood property, molecular marker, dendrogram and marker-trait association.

Addresses: H. Zheng, D. Hu, Y. Hao, Guangdong Provincial Key Laboratory of Bio-control for the Forest Disease and Pest, Guangdong Academy of Forestry, 510520 Guangzhou, Tel: +86-20-87033590; Fax: +86-20-87031245; People’s Republic of China, e-mail: zhenghq@sinogaf.cn

H. Duan, Y. Li, National Engineering Laboratory for Tree Breeding; College of Biological Sciences and Technology, Beijing Forestry University, 100083 Beijing, People's Republic of China

* These authors contributed equally to this work.

\section{Introduction}

Cunninghamia lanceolata (Lamb.) Hook, commonly known as Chinese fir, is one of the most important conifer tree species in China due to its great afforestation values in both timbers and ecological contributions. It has been cultivated for over 3,000 years and currently occupies $\sim 25 \%$ of man-made planta- 
Table 1. Descriptive statistics of the growth and wood property traits for fifty 24-year-old Chinese fir genotypes. H, height; $\mathrm{DBH}$, diameter at breast height; V, stem volume; WBD, wood basic density; Hy, hygroscopicity; HR, heart-wood ratio;

TL, tracheid length; TD, tracheid diameter; TLDR, tracheid length-diameter ratio; SD, standard deviation; F, the ANOVA (analysis of variance) parameter $\mathrm{F}\left({ }^{*} \mathrm{p}<0.05,{ }^{* *} \mathrm{p}<0.01\right) ; \mathrm{CV}$, coefficient of variation; R, repeatability

\begin{tabular}{|c|c|c|c|c|c|c|c|c|c|c|}
\hline No. & Genotype & $\mathrm{H}(\mathrm{m})$ & $\mathrm{DBH}(\mathrm{cm})$ & $\mathrm{V}\left(\mathrm{m}^{3}\right)$ & WBD $\left(\mathrm{g} / \mathrm{cm}^{3}\right)$ & Hy $(\%)$ & $\operatorname{HR}(\%)$ & $\mathrm{TL}(\mu \mathrm{m})$ & $\mathrm{TD}(\mu \mathrm{m})$ & TLDR \\
\hline 1 & $\mathrm{c} 17$ & 13.0 & 26.0 & 0.3792 & 0.2713 & 304.3 & 53.8 & 3030.3 & 46.0 & 73.1 \\
\hline 2 & c18 & 13.5 & 28.7 & 0.4565 & 0.3170 & 250.9 & 55.4 & 3065.7 & 47.4 & 78.3 \\
\hline 3 & c22 & 12.3 & 27.2 & 0.3924 & 0.3093 & 264.6 & 47.3 & 3097.4 & 42.5 & 71.0 \\
\hline 4 & c49 & 13.7 & 30.3 & 0.5157 & 0.2965 & 272.7 & 52.3 & 3423.7 & 46.5 & 75.1 \\
\hline 5 & c51 & 15.0 & 35.7 & 0.7749 & 0.3038 & 264.0 & 59.0 & 3244.7 & 40.3 & 72.1 \\
\hline 6 & c53 & 12.8 & 28.4 & 0.4322 & 0.3134 & 254.8 & 50.0 & 3174.0 & 40.8 & 81.6 \\
\hline 7 & c5 54 & 14.8 & 34.0 & 0.6939 & 0.2673 & 309.0 & 60.9 & 3318.4 & 46.3 & 72.0 \\
\hline 8 & c58 & 11.7 & 20.9 & 0.2163 & 0.2800 & 292.6 & 42.2 & 3094.1 & 41.3 & 75.7 \\
\hline 9 & c59 & 13.5 & 30.5 & 0.5126 & 0.3027 & 267.4 & 51.1 & 3283.6 & 41.1 & 68.5 \\
\hline 10 & c62 & 12.5 & 27.7 & 0.3959 & 0.3153 & 251.9 & 51.1 & 3304.5 & 40.8 & 73.5 \\
\hline 11 & c70 & 13.0 & 28.7 & 0.4419 & 0.3215 & 246.9 & 44.2 & 3120.5 & 46.0 & 74.3 \\
\hline 12 & c73 & 12.3 & 29.3 & 0.4319 & 0.2720 & 304.4 & 49.6 & 3508.9 & 43.7 & 78.5 \\
\hline 13 & c78 & 12.7 & 26.9 & 0.3877 & 0.3662 & 207.9 & 52.9 & 3334.4 & 41.4 & 80.2 \\
\hline 14 & c80 & 14.3 & 34.7 & 0.6933 & 0.3054 & 262.4 & 54.6 & 3078.8 & 42.7 & 75.8 \\
\hline 15 & c87 & 11.0 & 21.8 & 0.2193 & 0.3319 & 237.3 & 44.7 & 3173.5 & 44.7 & 72.5 \\
\hline 16 & c91 & 12.0 & 24.0 & 0.2844 & 0.2959 & 274.3 & 46.4 & 2827.4 & 45.1 & 67.7 \\
\hline 17 & c97 & 12.8 & 27.7 & 0.4384 & 0.3119 & 259.4 & 57.7 & 3571.3 & 48.6 & 77.9 \\
\hline 18 & c98 & 13.0 & 30.0 & 0.4805 & 0.3252 & 242.9 & 57.8 & 3398.1 & 54.5 & 90.4 \\
\hline 19 & c99 & 13.3 & 29.6 & 0.4956 & 0.3389 & 230.3 & 55.8 & 2729.5 & 42.5 & 63.8 \\
\hline 20 & c100 & 12.0 & 25.2 & 0.3146 & 0.3246 & 243.1 & 51.1 & 3398.8 & 45.1 & 67.9 \\
\hline 21 & c101 & 12.7 & 27.8 & 0.4138 & 0.3292 & 241.5 & 48.5 & 3162.2 & 44.3 & 66.6 \\
\hline 22 & c102 & 15.5 & 35.8 & 0.7891 & 0.3225 & 244.7 & 67.4 & 3224.4 & 42.1 & 71.5 \\
\hline 23 & c103 & 15.7 & 35.7 & 0.7952 & 0.2790 & 293.2 & 58.5 & 3555.6 & 49.0 & 77.2 \\
\hline 24 & c104 & 14.7 & 32.4 & 0.6453 & 0.2790 & 293.2 & 58.5 & 3555.6 & 49.0 & 77.2 \\
\hline 25 & c106 & 14.0 & 33.9 & 0.6507 & 0.3204 & 247.3 & 60.8 & 3363.3 & 44.1 & 72.9 \\
\hline 26 & c107 & 11.5 & 27.4 & 0.3586 & 0.2995 & 268.5 & 48.3 & 3286.9 & 50.8 & 67.9 \\
\hline 27 & c108 & 13.5 & 31.6 & 0.5465 & 0.3479 & 224.8 & 66.0 & 3461.5 & 42.0 & 71.1 \\
\hline 28 & c109 & 14.0 & 33.1 & 0.6248 & 0.3012 & 266.7 & 68.3 & 3311.7 & 44.6 & 72.2 \\
\hline 29 & c125 & 11.5 & 26.1 & 0.3280 & 0.2667 & 310.0 & 59.9 & 3285.8 & 53.1 & 75.2 \\
\hline 30 & c129 & 12.0 & 27.6 & 0.3867 & 0.3013 & 266.6 & 61.9 & 3748.5 & 43.7 & 63.0 \\
\hline 31 & c130 & 13.5 & 38.9 & 0.8666 & 0.2970 & 272.8 & 61.5 & 3282.3 & 41.5 & 62.2 \\
\hline 32 & c134 & 13.7 & 30.7 & 0.5247 & 0.2563 & 325.8 & 50.0 & 3125.9 & 52.8 & 73.8 \\
\hline 33 & c135 & 15.7 & 39.7 & 0.9800 & 0.2774 & 298.8 & 56.0 & 3071.5 & 49.9 & 70.3 \\
\hline 34 & c139 & 12.3 & 27.0 & 0.3893 & 0.2903 & 284.5 & 58.1 & 3223.8 & 45.9 & 75.2 \\
\hline 35 & c142 & 11.8 & 23.5 & 0.2748 & 0.3467 & 229.7 & 57.1 & 3298.5 & 48.0 & 71.8 \\
\hline 36 & c39 & 11.3 & 28.8 & 0.3903 & 0.3226 & 254.4 & 60.9 & 3122.8 & 44.9 & 67.6 \\
\hline 37 & $c 43$ & 15.8 & 42.8 & 1.1422 & 0.2584 & 321.7 & 50.8 & 3242.6 & 47.0 & 75.8 \\
\hline 38 & $c 44$ & 13.0 & 27.9 & 0.4223 & 0.2975 & 270.8 & 58.9 & 3688.3 & 48.0 & 82.7 \\
\hline 39 & c28 & 15.5 & 37.9 & 0.8874 & 0.3042 & 264.0 & 57.9 & 3191.6 & 42.8 & 68.1 \\
\hline 40 & c69 & 15.0 & 34.3 & 0.7216 & 0.2951 & 285.1 & 52.9 & 3168.2 & 48.1 & 84.7 \\
\hline 41 & c148 & 14.3 & 30.9 & 0.5560 & 0.3250 & 243.2 & 57.7 & 3370.9 & 48.3 & 79.7 \\
\hline 42 & c36 & 12.5 & 30.9 & 0.4878 & 0.2900 & 279.5 & 60.0 & 3647.6 & 44.7 & 61.9 \\
\hline 43 & c37 & 12.0 & 29.6 & 0.4355 & 0.3282 & 239.5 & 63.8 & 3761.0 & 50.7 & 70.7 \\
\hline 44 & c149 & 12.7 & 27.1 & 0.4280 & 0.2767 & 297.9 & 51.0 & 3490.5 & 47.8 & 59.2 \\
\hline 45 & c6 & 12.7 & 28.8 & 0.4467 & 0.3461 & 223.9 & 60.5 & 3620.7 & 44.5 & 69.5 \\
\hline 46 & c16 & 12.3 & 25.6 & 0.3374 & 0.2931 & 277.0 & 55.2 & 2989.7 & 41.0 & 70.4 \\
\hline 47 & $c 63$ & 12.3 & 24.0 & 0.2964 & 0.3115 & 256.1 & 44.1 & 2834.1 & 42.9 & 71.3 \\
\hline 48 & c10 & 14.5 & 34.7 & 0.7087 & 0.2933 & 279.1 & 46.6 & 3093.4 & 47.6 & 61.9 \\
\hline 49 & c23 & 12.8 & 28.1 & 0.4155 & 0.3249 & 244.5 & 56.9 & 3213.1 & 43.4 & 76.0 \\
\hline \multirow[t]{6}{*}{50} & c29 & 13.3 & 29.7 & 0.4825 & 0.2898 & 283.8 & 59.6 & 3195.6 & 44.5 & 65.9 \\
\hline & Mean & 13.2 & 30.0 & 0.5138 & 0.3048 & 266.6 & 55.1 & 3275.3 & 45.5 & 72.5 \\
\hline & SD & 1.3 & 4.6 & 0.1992 & 0.0246 & 26.7 & 6.2 & 227.7 & 3.5 & 6.2 \\
\hline & F & $4.64^{* *}$ & $4.63^{* *}$ & $4.87^{* *}$ & $2.50^{* *}$ & $2.50^{* *}$ & $1.71^{*}$ & $1.56^{*}$ & $3.65^{* *}$ & $1.75^{* *}$ \\
\hline & $C V(\%)$ & 7.7 & 12.7 & 31.3 & 9.2 & 11.5 & 10.0 & 9.7 & 6.8 & 11.8 \\
\hline & $\mathrm{R}$ & 0.78 & 0.78 & 0.79 & 0.60 & 0.60 & 0.42 & 0.36 & 0.73 & 0.43 \\
\hline
\end{tabular}


tions in southern China (Shi et al. 2010). Based on the knowledge and availability of genetic variability for selection (Bian et al. 2014), remarkable successes in breeding have already been achieved for this species, e.g. large-scale collection of elite germplasms, establishment of first and second and third generation seed orchards, and significant gains of superior clones. However, in most of the case, only a small proportion of the variability is actually used in the breeding programs, which finally results in a narrowing genetic base for further breeding. While a considerable number of potential elite germplasms (genotypes) conserved in ex situ banks were underutilized and frequently redundant because of the lack of adequate passport data for most of the lines. Thus, proper characterization of these genetic resources appeared to be highly required.

Diversity in trees could be assessed by measuring variation in phenotypic/morphological traits such as flowers, fruits, growth habit, and quantitative agronomic/economical traits like yield potential and wood property traits, etc., which are of direct interest to breeders, but this approach has certain limitations: (1) insufficient genetic information obtained, and (2) strong influence of genotype $\times$ environment $(G \times E)$ interactions (Rao 2004; Nybom et al. 2014). Molecular technology offers an avenue for the determination of informative DNA variation complemented to phenotype regardless of growth, differentiation, development, or environmental effects (Agarwal et al. 2008; Zhao et al. 2009). Polymorphism uncovered by DNA markers enables the breeders to discriminate the germplasm at a very precise level and to elucidate the genetic structure, diversity and relationship, as well as the marker-trait associations. Among the present available marker systems, the PCR-based markers have become popular because their application does not need any prior sequence information, and is easy to performed (Tatikonda et al. 2009). SRAP (sequence-related amplified polymorphism) technique is one such PCR-base marker system widely used for the plant genetic/genomic studies ( $\mathrm{Li}$ and Quiros 2001; Budak et al. 2004; Baloch et al. 2010). It appeared to be simple, efficient and cost-effective. Typically, it specifically targeted to the genome open reading frame (ORF) sequences providing more genetic information associated with phenotype (Ferriol et al. 2003; Uzun et al. 2009; Castonguay et al. 2010; Rana et al. 2013).

The objectives of this study were to survey the variability of growth and wood property traits of 50 ex situ conserved Chinese fir genotypes and their SRAP polymorphisms in terms of genetic diversity and relationship and significant marker-trait associations, aiming to profile these germplasms properly for further breeding use.

\section{Materials and Methods}

\section{Plant materials}

Fifty Chinese fir genotypes were analyzed in this study (Table 1). The top 35 genotypes (No. 1 to 35 ) belonged to the Lechang provenance (Guangdong, China), and the next every three genotypes were derived from the provenance of Guangxi (No. 36 to 38), Guizhou (No. 39 to 41), Hunan (No. 42 to 44), Jiangxi (No. 45 to 47 ) and Fujian (No. 48 to 50 ) respectively (China). These genotypes were conserved in the Longshan State Forest Farm (Guangdong, China) by grafting with a Latin square design of 5 $\times 5 \mathrm{~m}$ spacing since 1985 . Each genotype has four ramets that presented to be similar in size and vigor. Trees were maintained through standard commercial practices. 24-year-old plants were then measured for the traits of height $(\mathrm{H})$ and diameter (diameter at breast height, DBH), and the randomly selected three ramets for each genotype were subjected to the wood quality analysis assay.

\section{Measurement of growth and wood property traits}

DBH was measured at $1.3 \mathrm{~m}$ by a measuring tape and $\mathrm{H}$ by poles for each tree. Stem volume (V) was calculated according to the formula of $\mathrm{V}=5.8777042$ $\times 10^{-5} \times \mathrm{DBH}^{1.9699831} \times \mathrm{H}^{0.8964616}$ (Zheng et al. 2012).

A $5.02 \mathrm{~mm}$ increment core was taken at breast height $(1.3 \mathrm{~m})$ from every sampled tree by using a tree growth cone, and immediately stored in a plastic tube with two ends sealed, and then subjected to the wood quality analysis assays. Wood basic density (WBD) was evaluated by using a water displacement method: weight in water $\left(\mathrm{W}_{1}\right)$ and oven dry weight $\left(\mathrm{W}_{2}\right)$ in grams were taken for every sample, and the WBD $\left(\mathrm{g} / \mathrm{cm}^{3}\right)$ was then estimated following the formula of $\mathrm{WBD}=1 /\left(\left(\mathrm{W}_{1} / \mathrm{W}_{2}\right)-0.346\right)$ (Zheng et al. 2012). While the hygroscopicity (Hy) can be evaluated according to the formula of $\mathrm{Hy}=\left(\mathrm{W}_{1}-\mathrm{W}_{2}\right) /$ $\mathrm{W}_{2}$. The heart-wood ratio (HR) was determined theoretically based the value of $\left(r^{2} \times \Pi\right) /\left(R^{2} \times \Pi\right)(r$ and $\mathrm{R}$ stand for the radius of heartwood and whole wood respectively). The tracheid length (TL) and diameter (TD) were assessed by the method as described by Huang et al. (2004)

\section{DNA extraction and SRAP procedure}

Total genomic DNA was extracted from the Chinese fir mature leaves with a DNAsecure Plant Kit (TIANGEN, Beijing, China). SRAP PCR amplifications were carried out using 35 optimal primer combinations including 16 forward primers (Me1, Me2, Me3, Me4, Me9, Me10, Me11, Me12, Me13, 
Table 2. Phenotypic correlations among growth and wood property traits in Chinese fir. H, height; $\mathrm{DBH}$, diameter at breast height; V, stem volume; WBD, wood basic density; Hy, hygroscopicity; HR, heart-wood ratio; TL, tracheid length; TD, tracheid diameter; TLDR, tracheid length-diameter ratio. ${ }^{*} \mathrm{p}<0.05,{ }^{* *} \mathrm{p}<0.01$

\begin{tabular}{|c|c|c|c|c|c|c|c|c|c|}
\hline & $\mathrm{H}$ & $\mathrm{DBH}$ & $\mathrm{V}$ & WBD & $\mathrm{Hy}$ & HR & $\mathrm{TL}$ & TD & TLDR \\
\hline $\mathrm{H}$ & 1.0000 & & & & & & & & \\
\hline DBH & $0.8678^{* *}$ & 1.0000 & & & & & & & \\
\hline V & $0.9024^{* *}$ & $0.9798^{* *}$ & 1.0000 & & & & & & \\
\hline WBD & $0.1577^{*}$ & $-0.2083^{* *}$ & $-0.2141^{* *}$ & 1.0000 & & & & & \\
\hline Hy & 0.1493 & $0.1983^{*}$ & $0.2067^{* *}$ & $-0.9912^{* *}$ & 1.0000 & & & & \\
\hline HR & $0.2117^{* *}$ & $0.3181^{* *}$ & $0.2724^{* *}$ & 0.0121 & -0.0200 & 1.0000 & & & \\
\hline $\mathrm{TL}$ & -0.0216 & 0.0446 & -0.0036 & -0.0369 & 0.0354 & $0.1987^{*}$ & 1.0000 & & \\
\hline $\mathrm{TD}$ & 0.0550 & 0.0350 & 0.0490 & -0.1107 & 0.1253 & 0.0892 & 0.1135 & 1.0000 & \\
\hline TLDR & 0.0492 & -0.0641 & -0.0402 & 0.0490 & -0.0308 & 0.0318 & 0.0634 & $0.1632 *$ & 1.0000 \\
\hline
\end{tabular}

Table 3. The employed SRAP primer combinations and their performance in Chinese fir $(n=50)$. TNB, total number of bands; NPB, number of polymorphic bands; PPB, percentage of polymorphic bands; PIC, polymorphic information content; MI, marker index; RP, resolving power; h, Nei’s gene diversity ; I, Shannon's Information Index; SD, standard deviation

\begin{tabular}{|c|c|c|c|c|c|c|c|c|}
\hline SRAP Primer combination (forward/reverse, sequence 5' to 3') & TNB & NPB & $\begin{array}{l}\text { PPB } \\
(\%)\end{array}$ & PIC & MI & RP & h & I \\
\hline Me1(TGAGTCCAAACCGGATA)/Em1(GACTGCGTACGAATTAAT) & 12 & 12 & 100.0 & & 3.768 & & & 0.486 \\
\hline & & & & & & & & .458 \\
\hline Me1(TGAGTCCAAACCGGATA)/Em20(GACTGCGTACGAATTTAG) & 9 & 9 & 100.0 & .284 & & & .248 & 395 \\
\hline Me2(TGAGTCCAAACCGGAGC)/Em26(GACTGCGTACGAATTCGG) & & 13 & & & & & & 391 \\
\hline Me3 (TGAGTCCAAACCGGAAT)/Em17(GACTGCGTACGAATTATG) & & 11 & & & & & & 442 \\
\hline Me4(TGAGTCC & 15 & & 100.0 & & & & & .464 \\
\hline & & & & & & & & .444 \\
\hline Me9(TGAGTCCAAACCGGACA)/Em14 & 15 & 13 & 86.7 & & 3.511 & & 0.273 & 0.419 \\
\hline Me10(TGAGTCCAAACCGGACG)/Em20(GACTGCGTACGAATTTAG) & 1 & 12 & .3 & & 3.612 & & & 0.465 \\
\hline & & 12 & 2.3 & 0.271 & & & & 0.410 \\
\hline Me10(TGAGTCCAAACCGGACG)/Em2 & & & & & & & & 0.489 \\
\hline & & 16 & 88.9 & 0.271 & & & & 0.436 \\
\hline $\operatorname{Me} 11(\mathrm{TC}$ & & & 93.3 & 0.300 & 199 & & & 0.477 \\
\hline & & 14 & & & & & & 0.391 \\
\hline & & 8 & & & & & & .390 \\
\hline & & & & & & & & \\
\hline Me12(TGAGTCCAAAC & & & & & & & & 0.555 \\
\hline & & & & & & & & \\
\hline & & & & 17 & & & & .324 \\
\hline & & & & & & & & .424 \\
\hline & & & & & & & & 0.426 \\
\hline & & & & & & & & 0.424 \\
\hline $\operatorname{Me16}(\mathrm{TC}$ & 18 & 16 & 88.9 & 0.235 & 3.760 & 6.0 & 0.236 & 0.369 \\
\hline Me17(TGAGTCCAAACCGGTAG)/Em19(GAC & & & & & & & & 0.440 \\
\hline $\operatorname{Me} 17(\mathrm{~T}$ & & & 100.0 & 0.291 & 4.947 & 7.6 & 0.310 & 0.472 \\
\hline Me18(TGAGTCCAAACCGGCAT)/Em19(GACTGCGTACGAATTACG) & & 13 & & 0.239 & 3.109 & 5. & 0.234 & 0.364 \\
\hline & & & & & & & & \\
\hline & 16 & 14 & & & & & & 0.480 \\
\hline & 14 & 13 & & & & & & 0.479 \\
\hline & 9 & 7 & 77.8 & 0.310 & 2.171 & 4.28 & & 0.439 \\
\hline & & & & & & 6.76 & & 0.487 \\
\hline Me20(TGAGTCCAAACCGGTGT)/Em17(GACTGCGTACGAATTATG) & 13 & 11 & 84.6 & 0.254 & 2.793 & 4.52 & 0.243 & 0.376 \\
\hline & & & & & & & 0.261 & 0.406 \\
\hline Me20(TGAGTCCAAACCGGTGT)/Em26(GACTGCGTACGAATTCGC & 13 & 12 & 92.3 & 0.278 & 3.336 & 5.00 & 0.274 & 0.423 \\
\hline Me21(TGAGTCCAAACCGGTCA)/Em19(GACTGCG & 11 & & 90.9 & 0.247 & 2.470 & 2.92 & 0.209 & 0.349 \\
\hline Total & 498 & & & - & - & - & - & - \\
\hline Mean & 14.2 & 12.7 & 89.9 & 0.277 & 3.560 & 5.79 & 0.279 & 0.427 \\
\hline SD & 2.4 & 2.6 & 7.3 & 0.026 & 0.792 & 1.44 & 0.038 & 0.050 \\
\hline
\end{tabular}


Me15, Me16, Me17, Me18, Me19, Me20 and Me21) and 11 reverse primers (Em1, Em5, Em13, Em14, Em17, Em18, Em19, Em20, Em21, Em22 and Em26) (Table 3). Each $25 \mu$ l PCR reaction mixture consisted of $0.5 \mu \mathrm{l}$ of genomic DNA (about $50 \mathrm{ng}$ ), $0.5 \mu \mathrm{l}$ forward primer $(10 \mu \mathrm{mol} / \mathrm{l}), 0.5 \mu \mathrm{l}$ reverse primer (10 $\mu \mathrm{mol} / \mathrm{l}), 12.5 \mu \mathrm{l} 2 \times$ Taq Plus PCR MasterMix (TIANGEN, Beijing, China) and $11 \mu$ l double distilled water. The thermal cycling condition was the same as that of Li and Quiros (2001). The PCR products were separated by electrophoresis through $2 \%$ agarose gels with DL2000 DNA markers (TIANGEN, Beijing, China) as references. The gels were then stained with ethidium bromide and visualized under UV light using a Universal Hood II imaging system (Bio-Rad, Hercules, CA, USA).

\section{Statistical analysis}

Phenotypic variability was displayed by the parameter of $F$ and $C V$ (coefficient of variation) as assessed by one-way analysis of variance (ANOVA) process in Statistical Analysis System (SAS V 8.1) (SAS Institute, Cary, North Carolina). Repeatability $(R)$ for each trait was evaluated with following formula: $R$ $=1-1 / F$. The phenotypic correlation coefficient for each pair of traits was calculated by SAS PROC CORR program.

The SRAP bands were scored manually and recorded as a binary matrix, with codon of 1 and 0 representing presence and absence of a band at a particular location in each lane respectively. The polymorphism information content (PIC) for each primer set was calculated with software PowerMarker V 3.25 (Liu and Muse 2005). The marker index (MI) could be estimated with the formula: $\mathrm{MI}=\mathrm{PIC}$ $\times$ NPB, where NPB is the number of polymorphic bands per primer set (Powell et al. 1996). The primer resolving power (RP) was evaluated using the formula: $\mathrm{RP}=\Sigma I_{b}$, where $I_{b}=1-(2 \times|0.50-p|)$, and $p$ is the proportion of the 50 genotypes containing the $I$ band (Prevost and Wilkinson 1999). The POPGENE $\mathrm{V} 1.31$ was employed to estimate the parameter of $\mathrm{h}$ (Nei's gene diversity) and I (Shannon's Information Index) (Yeh et al. 1999). The program GenAlEx V 6.5 incorporated with Microsoft Excel 2010 software was implemented to conduct the AMOVA (analysis of molecular variance) procedure (Peakall and Smouse 2012).

For cluster analysis, the Numerical Taxonomy Multivariate Analysis System (NTSYSpc V 2.10e) (Rohlf 2000) was applied to estimate the genetic similarities of the genotypes with the simple matching coefficient (SM) and Dice coefficient for phenotype and SRAP data respectively, and then separately generate a dendrogram using the unweighted pair group method with arithmetic average (UPGMA) with the SAHN module. The goodness-of-fit of the dendrogram to the original genetic similarity matrix was validated by measuring the Cophenetic Value $(\mathrm{COPH})$ and Matrix Comparison Plot (MXCOMP) using NTSYSpc packages.

Marker-trait association assessment was performed by software TASSEL V 5.0 with general linear model (GLM) and mixed linear model (MLM) (Bradbury et al. 2007). The identified markers displaying a statistic value of $\mathrm{p}<0.05$ in both models were regarded as the significant markers associated with traits.

\section{Results}

\section{Genotypic variation in growth and wood property traits}

All the growth and wood property traits varied significantly among genotypes $(n=50)$, as evidenced by ANOVA results ( $F$ value; Table 1$)$. It was also observed that the coefficient of variation $(C V)$ spanned from 6.8 (tracheid diameter) to $31.3 \%$ (stem volume) across traits. While the repeatability for the traits of height $(\mathrm{H}), \mathrm{DBH}$ (diameter at breast height), stem volume (V), and wood basic density (WBD), hygroscopicity (Hy), and tracheid diameter (TD) seemed to be relatively high $(\leq 0.6)$.

Further analysis revealed that the tree height, $\mathrm{DBH}, \mathrm{V}$ and HR (heart-wood ratio) were positively correlated to each other at a significant level ( $p$ $<0.01$ ), as shown in Table 2. Positive correlations were also found between $\mathrm{Hy}$ and $\mathrm{DBH}$ and $\mathrm{V}$, and for HR with TL (tracheid length) and TD with TLDR (tracheid length-diameter ratio) ( $p<0.05$ or 0.01 ). Typically, negative correlations were consistently observed between WBD and growth and Hy $(\mathrm{p}<0.05$ or 0.01$)$.

\section{Genotypic variation in SRAPs}

Thirty-five SRAP primer combinations consistently resulted in a detectable PCR profile with clear, stable and rich polymorphism bands as represented by Fig. 1. These primer sets produced 498 scorable bands including 445 polymorphic loci with a PPB (percentage of polymorphic bands) of $89.4 \%$ across the present Chinese fir genotypes (Table 3 ). The number of bands for each assay ranged from 9 (Me1/Em20 and Me19/Em22) to 18 (Me11/Em5, Me16/Em19 and Me20/Em19) with an average of 14.2 bands and 12.7 polymorphic loci per primer combination. The PPB varied from 69.2 (Me19/ Em1) to $100.0 \%$ (Me1/Em1, Me1/Em20, Me4/Em5, Me12/Em19 and Me17/Em21) with an average of 


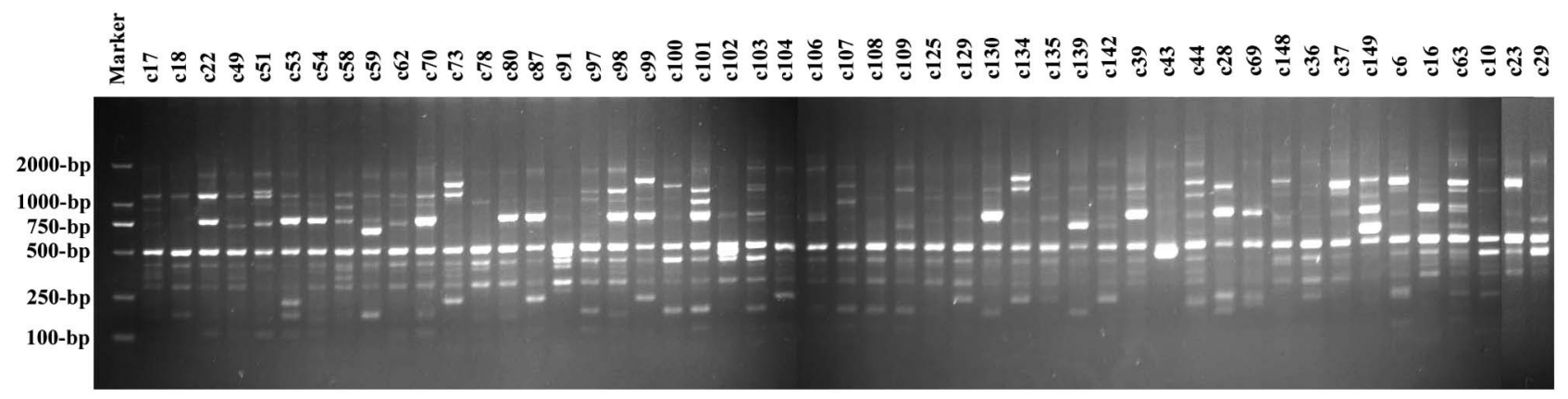

Fig. 1. The represented SRAP profile with primer combination Me20/Em19 for the present 50 Chinese fir genotypes

89.9\% per primer set. Each primer combination was found to express a reasonably informative PIC (polymorphic information content), MI (marker index) and RP (resolving power) for the genotypes with a stretching of $0.217-0.314$ (mean $=0.277), 2.123$ -5.115 (mean $=3.560)$ and $2.92-8.24$ (mean $=$ 5.79) respectively. While the Nei's gene diversity (h) ranged from 0.204 to 0.373 (mean $=0.279$ ), and the Shannon's Information Index (I) presented an average value of $0.427(0.324-0.555)$.

Significance $(p<0.01)$ of the variability of SRAP polymorphism among genotypes was further demonstrated by AMOVA (analysis of molecular variance) (Table 4). When considering the provenance aspect, it was also found that a total of $93.0 \%$ variation resided within provenances (Guangdong, Guangxi, Guizhou and Hunan, Jiangxi and Fujian), while there had low $(7.0 \%)$ but significant genetic variation among provenances. Typically, significant variation of the genotypes within Lechang provenance was observed at SRAPs.

\section{Clustering of genotypes}

For genotype clustering, we preliminarily constructed a dendrogram based on the growth and wood property data (matrix correlation $\mathrm{r}=0.98$ ) (Fig. $2 \mathrm{~A}$ ). It was found that the present 50 genotypes could be classified into 23 groups with a simple matching coefficient (SM) lower than 0.56. All the Groups seemed to harbor a limited number of members as less than five.

To further our understanding of the relationship of the genotypes at DNA level, UPGMA dendrogram was reconstructed with SRAP markers using DICE's coefficients (matrix correlation $r=0.73$ ) (Fig. 2 B). In general, the 50 Chinese fir genotypes could be grouped into 7 clusters (I to VII). Cluster I, II (except c28 from Guizhou), III, V and VI were composed by the genotypes derived from Lechang (Lechang provenance, Guangdong), while cluster IV harbor a complex origin (provenance) including those from Lechang (Guangdong, e.g. c125, c129, c130, c135 and c142), Guangxi (c39, c43 and c44), Guizhou (c69 and c148), Hunan (c36, c37 and c149), Jiangxi (c6, c16 and c63) and Fujian (c10). The genotypes of c23 and c29 were grouped into a separate cluster (VII) reflecting their closed relationship in provenance (Fujian).

\section{SRAP markers associated with growth and wood property traits}

In the next step, we aimed to determine the association of the SRAP markers with growth and wood property traits in Chinese fir. A total of 99 statistically significant $(p<0.05)$ marker-trait associations were detected using TASSEL as confirmed by both GLM and MLM (Table 5). These marker-trait associations corresponded to 77 different markers with $R^{2}$ (percentage of the phenotypic variation explained by marker) ranging from 8.3 to $26.4 \%$; 59 of these were found to be associated with only one trait, while the other 18 SRAP markers were linked to more than one traits (e.g. Me16/Em1 ${ }_{1000}$ significantly associated with $\mathrm{DBH}, \mathrm{V}, \mathrm{WBD}$ and Hy).

\section{Discussion}

In this study, we evidenced that the present 50 Chinese fir genotypes varied significantly in growth and wood property traits and SRAP polymorphisms suggesting a comprehensive diversity in phenotype

Table 4. Analysis of molecular variance (AMOVA)

\begin{tabular}{|c|c|c|c|c|c|c|c|c|}
\hline Source & $\mathrm{df}$ & SS & MS & Est. Var. & $\%$ & Stat & Value & $P$ value \\
\hline Within genotypes & 49 & 6981.760 & 142.485 & 71.242 & $100.0 \%$ & PhiPT & 1.000 & 0.001 \\
\hline Among provenances & 5 & 462.156 & 92.431 & 4.796 & $7.0 \%$ & PhiPT & 0.065 & 0.001 \\
\hline Within provenances & 44 & 3028.724 & 68.835 & 68.835 & $93.0 \%$ & PhiPT & 0.065 & 0.001 \\
\hline Within Lechang provenance & 34 & 4732.114 & 139.180 & 69.590 & $100.0 \%$ & PhiPT & 1.000 & 0.001 \\
\hline
\end{tabular}



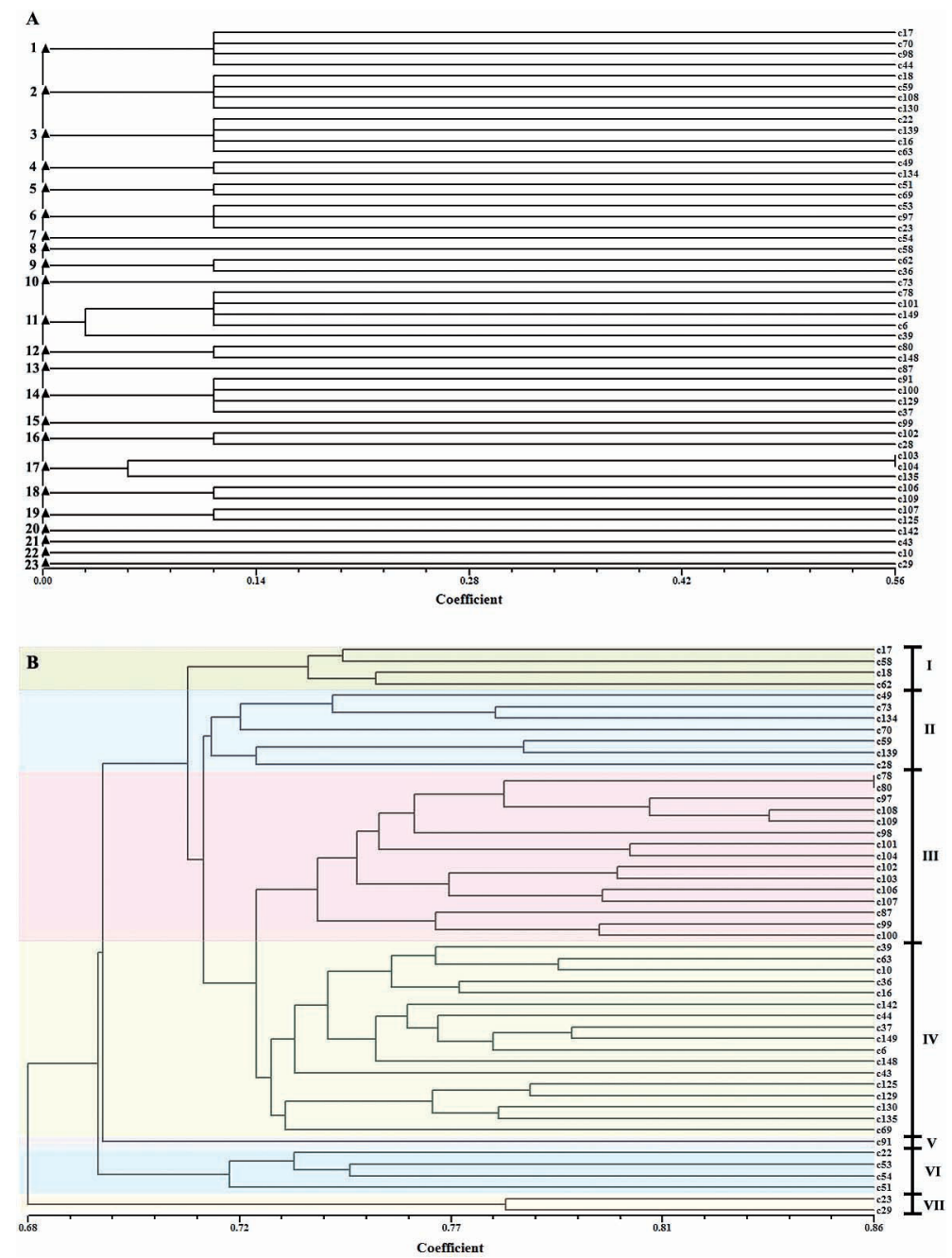

Fig. 2. UPGMA dendrograms of the Chinese fir genotypes based on growth and wood property data (A), and SRAP markers (B) respectively. A: Preliminary clustering is indicated with Arabic numerals followed by a black triangle; the coefficient was obtained by the simple matching method. B: Clusters are shown in different background, and indicated with scale and upper roman numerals; the coefficient was obtained by Dice method

and genotype. SRAP' clustering analysis further revealed that these genotypes could be split into 7 groups that help us to select the breeding parents with more distant genetic relationships. Herein, we also identified a set (77) of growth and wood property associated SRAP markers. These makers may be useful for the next marker-assisted selection (MAS) programs in Chinese fir.

To rapidly obtain the Chinese fir genetic information in genotypes, PCR-based SRAP marker technique was herein employed. In fact, several other PCR-based DNA marker systems have also been used for the germplasm evaluation of Chinese fir. Li et al. (2007) applied the RAPD markers to decipher the genetic diversity and relationships of 182 second-generation elite genotypes of Chinese fir based on 29 primers that generated a total of 311 fragments with a PPB of $78.8 \%$ and an average of 8.4 polymorphic bands per primer. Yang et al. (2009) reported a molecular polymorphic study of different geographic provenance germplasm $(n=24)$ of Chinese fir by ISSR markers. In their study, a total of 173 polymorphic bands were produced by 22 primers with an average of 7.9 polymorphic bands per primer. Recently, Wen et al. (2013) examined 27,666,670 Chinese fir transcriptome and finally identified 28 polymorphic useful EST-SSR markers. While Ouyang et al. (2014) developed 52 SSR markers from Chinese fir, and then successfully detected 254 polymorphic loci from a germplasm collection (1st breeding population) with an average of 4.9 alleles per loci. In this report, we observed that the SRAP system enabled to produce 498 bands with a PPB of $89.4 \%$ and an average of 12.7 polymorphic bands per primer combination in the tested genotypes. Furthermore, the marker attributes including PIC, MI and RP appeared to be rather informative for each primer set (Table 3 ). These performances suggested that the present SRAP system was also efficient for the detection of DNA variability of Chinese fir. Application of SRAP 
Table 5. SRAP markers associated with growth and wood property traits in Chinese fir. H, height; DBH, diameter at breast height; V, stem volume; WBD, wood basic density; Hy, hygroscopicity; HR, heart-wood ratio; TL, tracheid length; TD, tracheid diameter; TLDR, tracheid length-diameter ratio. Only the markers with significant marker-trait associations $(\mathrm{p}<0.05)$ in both GLM (general linear model) and MLM (mixed linear model) are mentioned. The maker is named with its original primer set followed by size $(\mathrm{bp}) \cdot R^{2}$ indicated the percentage of the phenotypic variation explained by marker. The value of $R^{2}$ was calculated by MLM

\begin{tabular}{|c|c|c|}
\hline Traits & The significantly associated SRAP markers $(\mathrm{p}<0.05)$ & $\begin{array}{l}\text { Range of } \mathrm{R}^{2} \\
(\%)\end{array}$ \\
\hline $\mathrm{H}$ & 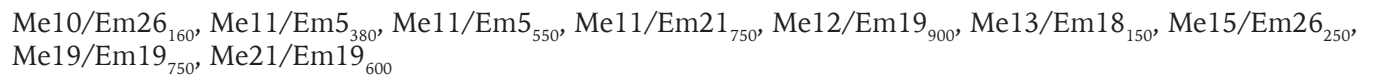 & $9.1-12.8$ \\
\hline DBH & 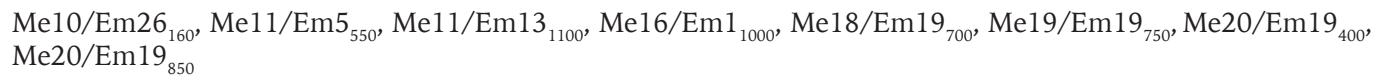 & $8.8-12.8$ \\
\hline $\mathrm{V}$ & $\mathrm{Me} 1 / \mathrm{Em}_{20} \mathrm{O}_{250}, \mathrm{Me} 10 / \mathrm{Em}_{2} 6_{160}, \mathrm{Me} 13 / \mathrm{Em} 18_{150}, \mathrm{Me} 16 / \mathrm{Em}_{1000}, \mathrm{Me} 17 / \mathrm{Em} 21_{2000}, \mathrm{Me} 20 / \mathrm{Em} 19_{400}$ & $8.4-16.1$ \\
\hline WBD & 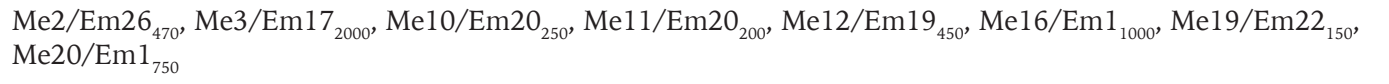 & $9.3-26.4$ \\
\hline HR & 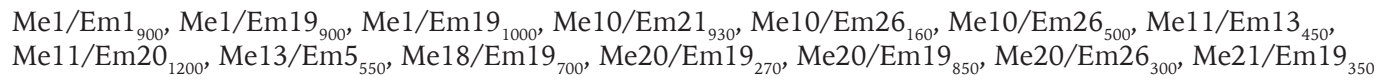 & $8.3-17.5$ \\
\hline Hy & $\begin{array}{l}\mathrm{Me} 2 / \mathrm{Em}_{26} 6_{40}, \mathrm{Me} 3 / \mathrm{Em} 17_{2000}, \mathrm{Me} 10 / \mathrm{Em}_{2} \mathrm{O}_{250}, \mathrm{Me} 11 / \mathrm{Em}_{20} \mathrm{O}_{200}, \mathrm{Me} 12 / \mathrm{Em}_{19}{ }_{450}, \mathrm{Me} 16 / \mathrm{Em} 1_{1000}, \mathrm{Me} 19 / \mathrm{Em} 22_{150} \\
\mathrm{Me} 20 / \mathrm{Em}_{750}\end{array}$ & $9.0-24.6$ \\
\hline $\mathrm{TL}$ & 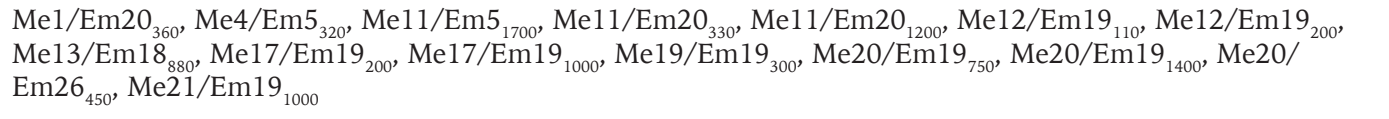 & $8.3-17.5$ \\
\hline TD & 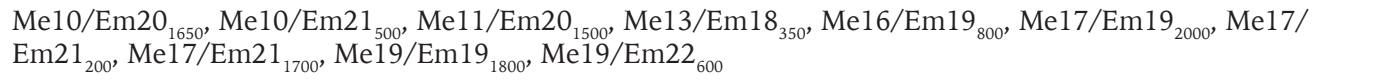 & $8.3-14.8$ \\
\hline TLDR & 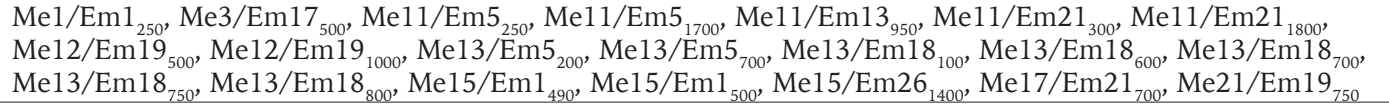 & $8.9-15.7$ \\
\hline
\end{tabular}

technique in conifer was additionally reported by Feng et al. (2009). In their study, nine SRAP primer pairs yielded 249 bands with a PPB of $55.42 \%$ from a total of 480 Pinus koraiensis samples that belonged to 24 difference provenances. Albeit so, there have few studies on the application of the SRAP technique in conifer.

Genetic diversity refers to the level of genetic differentiation within a species or population, which also reflects the ability of the germplasm to adapt to the changeable environments and its genetic potential for breeding (Cravero et al. 2007; Yu et al. 2014). In terms of the measurements of PPB (89.4\%), h (0.204-0.373, mean $=0.279)$ and I (0.324-0.555, mean $=0.427$, we found that the genetic diversity of the present Chinese fir genotypes was relatively high. This diversity furthered our understanding of the phenotypic variation in growth and wood property traits, and strongly suggested that it was possible to select the divergent germplasms (genotypes) for the breeding programs.

With respect to the genetic relationship, it is not always the best way to define the genetic similarity using the phenotypic traits because of the degree of divergence between genotypes at the phenotypic level is not necessarily correlated with a similar degree of genetic difference (Hamrick and Loveless 1989; Mwase et al. 2010). As shown in Fig. 2, the phenotypic dendrogram had low correspondence to the DNA tree. For example, the genotypes of c17, c70, c98 and c44 were considered to be classified into a group (group 1) in the phenotypic dendrogram, but according to the molecular (SRAP) distance matrix, they were distributed into 4 different clusters (I IV). Albeit the clustering of c18, c59, c108 and c130 in the phenotypic tree and their consistent Lechang origin, the SRAP dendrogram revealed that these genotypes belonged to different clusters at DNA level. This divergence can be largely explained by: (1) genetic interactions, i.e., two or more different combinations of genes may lead to same phenotype (Dillman et al. 1997; Oliveira et al. 2013), (2) limited phenotypic/morphological characters tested (Oliveira et al. 2013), i.e. only 9 quantitative traits (growth and wood property traits) were involved in this study, while higher amount of SRAP markers (TNB $=498, \mathrm{NPB}=445)$ was used, and (3) volatility of the phenotype influenced by the environmental factors. Indeed, when comparing the morphological and molecular clustering patterns it was commonly reported that these two methods were inconsistent and highly variable (Rana et al. 2005; Mamunur Rahman et al. 2011). Discrepancy of the genetic distances between morphological traits and molecular markers (AFLP) could also be found in the tree species Uapaca kirkiana müell. Årg (Mwase et al. 2010). In our study, the SRAP dendrogram definitely had higher discriminating capacity over that of phenotype, and it could be employed as an authentic reference for the assessment of the genetic relationship when these germplasms (genotypes) were considered to be used. 
Success of MAS depends on the availability of marker-trait associations. In this report, a total of 99 significant marker-trait associations corresponding to 77 different SRAP markers were detected (Table 5). These markers could explain 8.3 to $26.4 \%$ variation $\left(R^{2}\right)$ of the growth and wood property traits at a significant level $(p<0.05)$. Strikingly, 18 of which were found to be associated with more than one phenotypic traits. For example, Me19/Em19 was linked to $\mathrm{H}$ and $\mathrm{DBH}$, while $\mathrm{Me} 16 / \mathrm{Em}_{1} 1_{100}$ was accounted for both growth (DBH and V) and wood property (WBD and Hy) traits. Such associations may be caused by pleiotropism or QTL interactions (Wang et al. 2013), and also reflected a correlation between traits, in accordance with the results of Table 2. Collard et al. (2005) proposed that a QTL explaining more than $10.0 \%$ of total phenotypic variation $\left(R^{2}\right)$ could be considered as major QTL. Referring to this, 41 SRAP markers $\left(R^{2}>10.0 \%\right)$ corresponding to 53 marker-trait associations could be regarded as pivotal genetic loci for growth and wood property traits. One such marker, Me2/Em $26_{470}$, even explained more than $20.0 \%$ of the phenotypic variation for wood property traits $(26.4 \%$ and $24.6 \%$ for WBD and Hy respectively). Since the SRAP technique aimed to detect the functional genomic regions (Li and Quiros 2001), the present marker-trait associations seemed to be particularly useful for Chinese fir MAS programs.

\section{Acknowledgments}

This research was supported by the National Natural Sciences Foundation of China (No. 31200506), the Special Fund for Forest Scientific Research in the Public Welfare (No. 201404127) and the National '863' Project in the 12th Five-Year Plan in China (2011AA100203).

\section{References}

Agarwal M., Shrivastava N., Padh H. 2008. Advances in molecular marker techniques and their applications in plant sciences. Plant Cell Reports 27: 617-631.

Baloch F.S., Kurt C., Arioğlu H., Ozkan H. 2010. Assaying of diversity among soybean (Glycin max (L.) Merr.) and peanut (Arachis hypogaea L.) genotypes at DNA level. Turkish Journal of Agriculture and Forestry 34: 285-301.

Bian L., Shi J., Zheng R., Chen J., Wu H.X. 2014. Genetic parameters and genotype-environment interactions of Chinese fir (Cunninghamia lanceolata) in Fujian Province. Canadian Journal of Forest Research 44: 582-592.
Bradbury P.J., Zhang Z., Kroon D.E., Casstevens T.M., Ramdoss Y., Buckler E.S. 2007. TASSEL: Software for association mapping of complex traits in diverse samples. Bioinformatics 23: 2633-2635.

Budak H., Shearman R.C., Gaussoin R.E., Dweikat I. 2004. Application of sequence-related amplified polymorphism markers for characterization of turfgrass species. HortScience 39: 955-958.

Castonguay Y., Cloutier J., Bertrand A., Michaud R., Laberge S. 2010. SRAP polymorphisms associated with superior freezing tolerance in alfalfa (Medicago sativa spp. sativa). Theoretical and Applied Genetics 120: 1611-1619.

Collard B.C.Y., Jahufer M.Z.Z., Brouwer J.B., Pang E.C.K. 2005. An introduction to markers, quantitative trait loci (QTL) mapping and marker-assisted selection for crop improvement: The basic concepts. Euphytica 142: 169-196.

Cravero V., Martín E., Cointry E. 2007. Genetic diversity in Cynara cardunculus determined by sequence-related amplified polymorphism markers. Journal of the American Society for Horticultural Science 132: 208-212.

Dillman C., Bar-Hen A., Guérin D., Charcosset A., Murigneux A. 1997. Comparison of RFLP and morphological distances between maize Zea mays L. inbred lines. Consequences for germplasm protection purposes. Theoretical and Applied Genetics 95: 92-102.

Feng F., Chen M., Zhang D., Sui X., Han S. 2009. Application of SRAP in the genetic diversity of Pinus koraiensis of different provenances. African Journal of Biotechnology 8: 1000-1008.

Ferriol M., Picó B., Nuez F. 2003. Genetic diversity of a germplasm collection of Cucurbita pepo using SRAP and AFLP markers. Theoretical and Applied Genetics 107: 271-282.

Hamrick J.L., Loveless M.D. 1989. The genetic structure of tropical tree populations: associations with reproductive biology. In: The evolutionary ecology of plants. Bock J.H., Linhart Y.B. (eds.). Westview Press, Boulder, pp 129-146.

Huang S., Zhou C., Zhu L., Wei L., Shi J., Liu M. 2004. Study on the genetic variation of growth traits and wood properties for Chinese fir half-sib families. Guangxi Zhiwu 24: 535-539 (Chinese with English abstract).

Li G., Quiros C.F. 2001. Sequence-related amplified polymorphism (SRAP), a new marker system based on a simple PCR reaction: its application to mapping and gene tagging in Brassica. Theoretical and Applied Genetics 103: 455-461.

Li M., Shi J., Li F., Gan S. 2007. Molecular characterization of elite genotypes within a second-generation Chinese fir (Cunninghamia lanceolata) breeding population using RAPD markers. Scientia Silvae Sinicae 43: 50-55. 
Liu K., Muse S.V. 2005. PowerMarker: an integrated analysis environment for genetic marker analysis. Bioinformatics 21: 2128-2129.

Mamunur Rahman M., Hussain A., Syed M.A., Ansari A., Mahmud M.A.A. 2011. Comparison among clustering in multivariate analysis of rice using morphological traits, physiological traits and simple sequence repeat markers. American-Eurasian Journal of Agricultural and Environmental Sciences 11: 876-882.

Mwase W.F., Akinnifesi F.K., Stedjec B., Kwapata M.B., Bjørnstad Å. 2010. Genetic diversity within and among Southern African provenances of $U a$ paca kirkiana müell. Årg using morphological and AFLP markers. New Forests 40: 383-399.

Nybom H., Weising K., Rotter B. 2014. DNA fingerprinting in botany: past, present, future. Investigative Genetics 5: 1 .

Oliveira F.I.C., Bordallo P.N., Castro A.C.R., Correia D. 2013. Genetic diversity of spineless Cereus jamacaru accessions using morphological and molecular markers. Genetics and Molecular Research 12: 4586-4594.

Ouyang L., Chen J.H., Zheng R.H., Xu Y., Lin Y.F., Huang J.H., Ye D.Q., Fang Y.H., Shi J.S. 2014. Genetic diversity among the germplasm collections of the Chinese fir in 1 st breeding population upon SSR markers. Journal of Nanjing Forestry University (Natural Science Edition) 38: 21-26 (In Chinese with English abstract).

Peakall R., Smouse P.E. 2012. GenAlEx 6.5: genetic analysis in Excel. Population genetic software for teaching and research-an update. Bioinformatics 28: 2537-2539.

Powell W., Morgante M., Andre C., Hanafey M., Vogel J., Tingey S., Rafalski A. 1996. The comparison of RFLP, RAPD, AFLP and SSR (microsatellite) markers for germplasm analysis. Molecular Breeding 2: 225-238.

Prevost A., Wilkinson M.J. 1999. A new system of comparing PCR primers applied to ISSR fingerprinting of potato cultivars. Theoretical and Applied Genetics 98: 107-112.

Rana M.K., Singh V.P., Bhat K.V. 2005. Assessment of genetic diversity in upland cotton (Gossypium hirsutum L.) breeding lines by using amplified fragment length polymorphism (AFLP) markers and morphological characteristics. Genetic Resources and Crop Evolution 52: 989-997.

Rana M.K., Arora K., Singh S., Singh A.K. 2013. Multi-locus DNA fingerprinting and genetic diversity in jute (Corchorus spp.) based on sequence-related amplified polymorphism. Journal of Plant Biochemistry and Biotechnology 22: 1-8.

Rao N.K. 2004. Plant genetic resources: Advancing conservation and use through biotechnology. African Journal of Biotechnology 3: 136-145.
Rohlf J.F. 2000. NTSYSpc: numerical taxonomy and multivariate analysis system. Exeter Software, Setauket, New York, USA.

Shi J., Zhen Y., Zheng R.H. 2010. Proteome profiling of early seed development in Cunninghamia lanceolata (Lamb.) Hook. Journal of Experimental Botany 61: 2367-2381.

Tatikonda L., Wani S.P., Kannan S., Beerelli N., Sreedevi T.K., Hoisington D.A., Devi P., Varshney R.K. 2009. AFLP-based molecular characterization of an elite germplasm collection of Jatropha curcas L., a biofuel plant. Plant Science 176: 505513.

Uzun A., Yesiloglu T., Aka-Kacar Y., Tuzcu O., Gulsen O. 2009. Genetic diversity and relationships within Citrus and related genera based on sequence related amplified polymorphism markers (SRAPs). Scientia Horticulturae 121: 306-312.

Wang X.Q., Yu Y., Li W., Guo H.L., Lin Z.X., Zhang X.L. 2013. Association analysis of yield and fiber quality traits in Gossypium barbadense with SSRs and SRAPs. Genetics and Molecular Research 12: 3353-3362.

Wen Y., Ueno S., Han W., Tsumura Y. 2013. Development and characterization of 28 polymorphic EST-SSR markers for Cunninghamia lanceolata (Taxodiaceae) based on transcriptome sequences. Silvae Genetica 62: 137-141.

Yang Y.L., Ma X.Q., Zhang M.Q. 2009. Molecular polymorphic analysis for different geographic provenances of Chinese fir. Journal of Tropical and Subtropical Botany 17: 183-189 (In Chinese with English abstract).

Yeh F.C., Yang R.C., Boyle T. 1999. PopGene: Microsoft Window-based freeware for population genetic analysis, version 1.31. Edmonton: University of Alberta and Center for International Forestry Research.

Yu J., Jing Z.B., Cheng J.M. 2014. Genetic diversity and population structure of Stipa bungeana, an endemic species in Loess Plateau of China, revealed using combined ISSR and SRAP markers. Genetics and Molecular Research 13: 1097-1108.

Zhao W.G., Fang R.J., Pan Y.L., Yang Y.H., Chung J.W., Il-Min, Chung IIM, Park Y.J. 2009. Analysis of genetic relationships of mulberry (Morus L.) germplasm using sequence-related amplified polymorphism (SRAP) markers. African Journal of Biotechnology 8: 2604-2610.

Zheng H.Q., Liang R.Y., Hu D.H., Wei R.P., Wang R.H., Yan S. 2012. Selection of large-sized Cunninghamia lanceolata superior trees and variation analysis on the major economic traits. Journal of Southwest Forestry University 32: 26-29 (In Chinese with English abstract). 